\title{
Duration of antibiotic treatment and risk of recurrence after surgical management of orthopaedic device infections: a multicenter case-control study
}

Romy Spitzmüller ${ }^{1 *}$ (D), Denis Gümbel ${ }^{1,2}$, Claas Güthoff ${ }^{3}$, Sarah Zaatreh $^{4}$, Annett Klinder $^{4}$, Matthias Napp ${ }^{1}$, Rainer Bader ${ }^{4}$, Wolfram Mittelmeier ${ }^{4}$, Axel Ekkernkamp ${ }^{1}$, Axel Kramer ${ }^{5}$ and Dirk Stengel ${ }^{6}$

\begin{abstract}
Background: Device-related infections in orthopaedic and trauma surgery are a devastating complication with substantial impact on morbidity and mortality. Systemic suppressive antibiotic treatment is regarded an integral part of any surgical protocol intended to eradicate the infection. The optimal duration of antimicrobial treatment, however, remains unclear. In a multicenter case-control study, we aimed at analyzing the influence of the duration of antibiotic exposure on reinfection rates 1 year after curative surgery.

Methods: This investigation was part of a federally funded multidisciplinary network project aiming at reducing the spread of multi-resistant bacteria in the German Baltic region of Pomerania. We herein used hospital chart data from patients treated for infections of total joint arthroplasties or internal fracture fixation devices at three academic referral institutions. Subjects with recurrence of an implant-related infection within 1 year after the last surgical procedure were defined as case group, and patients without recurrence of an implant-related infection as control group. We placed a distinct focus on infection of open reduction and internal fixation (ORIF) constructs. Uni- and multivariate logistic regression analyses were employed for data modelling.

Results: Of 1279 potentially eligible patients, 269 were included in the overall analysis group, and 84 contributed to an extramedullary fracture-fixation-device sample. By multivariate analysis, male sex (odds ratio [OR] 2.06, 95\% confidence interval $[\mathrm{Cl}] 1.08$ to $3.94, p=0.029$ ) and facture fixation device infections (OR 2.05, 95\% Cl 1.05 to 4.02 , $p=0.036$ ) remained independent predictors of reinfection. In the subgroup of infected ORIF constructs, univariate point estimates suggested a nearly $60 \%$ reduced odds of reinfection with systemic fluoroquinolones (OR $0.42,95 \%$ $\mathrm{Cl} 0.04$ to 2.46 ) or rifampicin treatment (OR $0.41,95 \% \mathrm{Cl} 0.08$ to 2.12 ) for up to 31 days, although the width of confidence intervals prohibited robust statistical and clinical inferences.

Conclusion: The optimal duration of systemic antibiotic treatment with surgical concepts of curing wound and device-related orthopaedic infections is still unclear. The risk of reinfection in case of infected extramedullary fracture-fxation devices may be reduced with up to 31 days of systemic fluoroquinolones and rifampicin, although scientific proof needs a randomized trial with about 1400 subjects per group. Concerted efforts are needed to determine which antibiotics must be applied for how long after radical surgical sanitation to guarantee sustainable treatment success.
\end{abstract}

Keywords: Implant-associated infections, Antibiotic treatment, Reinfection, Orthopaedic devices

\footnotetext{
* Correspondence: romy.spitzmueller@googlemail.com

'Department of Trauma, Reconstructive Surgery and Rehabilitation Medicine,

University Medicine Greifswald, Ferdinand-Sauerbruch-Str, 17475 Greifswald,

Germany

Full list of author information is available at the end of the article
}

(c) The Author(s). 2019 Open Access This article is distributed under the terms of the Creative Commons Attribution 4.0 International License (http://creativecommons.org/licenses/by/4.0/), which permits unrestricted use, distribution, and reproduction in any medium, provided you give appropriate credit to the original author(s) and the source, provide a link to the Creative Commons license, and indicate if changes were made. The Creative Commons Public Domain Dedication waiver (http://creativecommons.org/publicdomain/zero/1.0/) applies to the data made available in this article, unless otherwise stated. 


\section{Background}

Surgical site infections (SSI), including deep, implant-associated infections, remain serious complications in orthopaedic surgery, with marked impact on morbidity and mortality. They often result in multiple revisions, poor functional and health-related outcomes, and significant financial burden to health care systems worldwide [1-6].

Joint arthroplasty registries have greatly contributed to the knowledge about the risk of infection in high-income countries. Various definitions of SSI, follow-up intervals, and effect modifiers like age, co-morbidity, treatment indication, type of components etc. notwithstanding, national benchmarks typically range from 0.5 to $2.0 \%$ in primary, elective total hip and knee replacement [7-10]. Revision arthroplasty, however, is associated with a more than twofold risk of infection $[9,11-13]$.

In contrast, SSI after fracture fixation are far less understood, and registry or other large-scale data are generally missing. Numerous, often combined approaches are used for surgical fracture stabilization (e.g., primary external fixation followed by open reduction and internal fixation [ORIF], intramedullary nail fixation plus ORIF for a fracture of the distal fibula, ORIF of the tibia plafond plus nail of the fibula, etc.) conditional on the individual anatomical site, joint and soft tissue compromise, individual patient profiles, and so on. Plate and screw constructs are obviously at the highest risk of infection, even if ORIF is performed in a minimally-invasive fashion. The reported average SSI incidence rate after surgical fixation of lower extremity fractures is about 5\% [14-22]. Yet, in case of open fractures and severe soft tissue injury, the risk of infection with both extra- and intramedullary fixation may far exceed $10 \%$ [23-25].

Key principles of preventing surgical site and implant-associated infections comprise proper skin disinfection [26], peri-operative antibiotic prophylaxis [27], use of antibiotic-loaded cements in hip and knee arthroplasty [28], intra-operative warming [29], irrigation of fracture wounds [25] and many others. In elective arthroplasty, current care bundles include pre-operative screening for MRSA carriage [30] and eradication of staphylococci by nasal mupirocin ointment and body washing [31-34]. In orthopaedic trauma, adequate timing of definitive fracture fixation (i.e., after damage-control, if necessary) $[35,36]$ remains a mainstay of preventing deep infections and other complications. Minimally-invasive access routes and biologically designed implants may further decrease the risk of infection because of less trauma to surrounding soft tissues, thereby avoiding a surgical second hit [37]. While all these interventions proved effective in reducing the incidence of SSI [38-40], the total number of infections is expected to rise globally because of an increasing number of orthopaedic procedures performed on an aging population with multiple risk factors (e.g., obesity, nicotine abuse, diabetes mellitus and other chronic diseases) [2, 41].

Deep SSI, specifically implant-related infections, demand aggressive surgical management. Decisive factors are the type of implant (i.e., arthroplasty or fracture fixation device), early or late onset of infection, stability etc., conditionally prompting serial debridement, oneor two-stage revision, septic arthrodesis, or complex reconstruction including muscle flaps or other types of tissue transfer [42-45]. Regardless of the particular device and primary indication for its use, systemic antibiotics are widely regarded a mainstay in treating implant-associated orthopaedic infections of any cause, although their role is currently not fully understood. As it is consensus that most available systemic antimicrobials cannot penetrate biofilms and destroy sessile bacteria, they may suppress or kill pathogens released from implant surfaces in their planktonic state $[42-44,46]$. Current practice guidelines and expert consensus statements recommend systemic antibiotics to be applied for 2 weeks up to 3 months with or following a clear, potentially curative surgical concept $[43,44]$. As antibiotic treatment potentially induces microbial resistance and causes adverse events, it must be as short as possible but as long as necessary.

The aim of the present multicenter case-control study was to investigate the influence of the duration of antibiotic treatment on the rate of recurrence (i.e., treatment failure) after surgical management of various orthopaedic device-related infections. Give the paucity of data and absence of clear-cut recommendations in this setting, we placed a focus on infected osteosynthesis constructs, namely extramedullary implant infections.

\section{Methods \\ General remarks}

This was a multi-institutional case-control study conducted at three academic tertiary referral hospitals in Germany (i.e., one university supra-regional trauma center, one maximum-care university orthopaedic joint replacement facility, and one supra-regional trauma center of the Federal Statutory Accident Insurance). This investigation was part of a larger network project aiming at preventing the spread of multi-resistant bacteria in the German Baltic region and Federal State of Mecklenburg-West-Pomerania, as funded by the German Ministry of Education and Research (BMBF). Details of the project can be assessed at http://www. hicare.de. All individual project modules, including this investigation, received ethical approval by the central and local Institutional Review Boards (IRB), and fully 
complied with national and European laws of data safety and protection.

\section{Research question}

We posed the following primary research question in a PICOT (patient and problem, intervention, control, outcome, time) format:

"In patients with an infected total joint arthroplasty or fracture fixation device demanding surgical revision, does the duration of systemic antimicrobial treatment impact the risk of re-infection within one year after the final surgical procedure?"

We decided to break down the overall dataset to answer the following, more specific secondary PICOT question:

"In patients with an infected extramedullary fracture fixation device demanding surgical revision, does the duration of systemic antimicrobial treatment impact the risk of re-infection within one year after the final surgical procedure?"

\section{Definition of cases and controls}

We defined cases as patients who sustained any reinfection demanding any surgical revision $\leq 1$ year after the index procedure. Controls were defined as patients who did not sustain any infection demanding surgical revision (or any surgical revision for infection) $\leq 1$ year, being aware the control status is fragile and may change to a case status with longer follow-up intervals. Given the catchment area and healthcare mandate of recruiting centers we presumed that patients normally followed-up as outpatients who did no longer show up or were admitted for reinfection within 1 year represented controls.

\section{Data acquisition and storage}

Hospital databases were searched for eligible patients with the diagnosis of infection of total joint replacements or fracture fixation devices between 1999 and 2014 using ICD-10 codes T84.5 to 84.7 (complications caused by orthopaedic arthroplasties or implants) and M86.0 to M86.9 (osteomyelitis). Individual electronic and paper hospital charts were thoroughly reviewed to identify patients with an infection of a total hip or knee joint replacement, or infection of an osteosynthesis construct of the humerus, forearm, femur, tibia, fibula, ankle, or calcaneus were included in the study. Apart from $\geq 1$ documented surgical procedure intended to cure the initial and reinfection (e.g., one- or two-stage revision with or without component retention or exchange, implant removal etc.) $[47,48]$, diagnostic criteria were documented clinical signs (e.g., warming, swelling, fever), presence of a sinus tract, inflammatory markers in peripheral blood (e.g., C-reactive protein [CRP], white blood cell count), and positive microbiological cultures

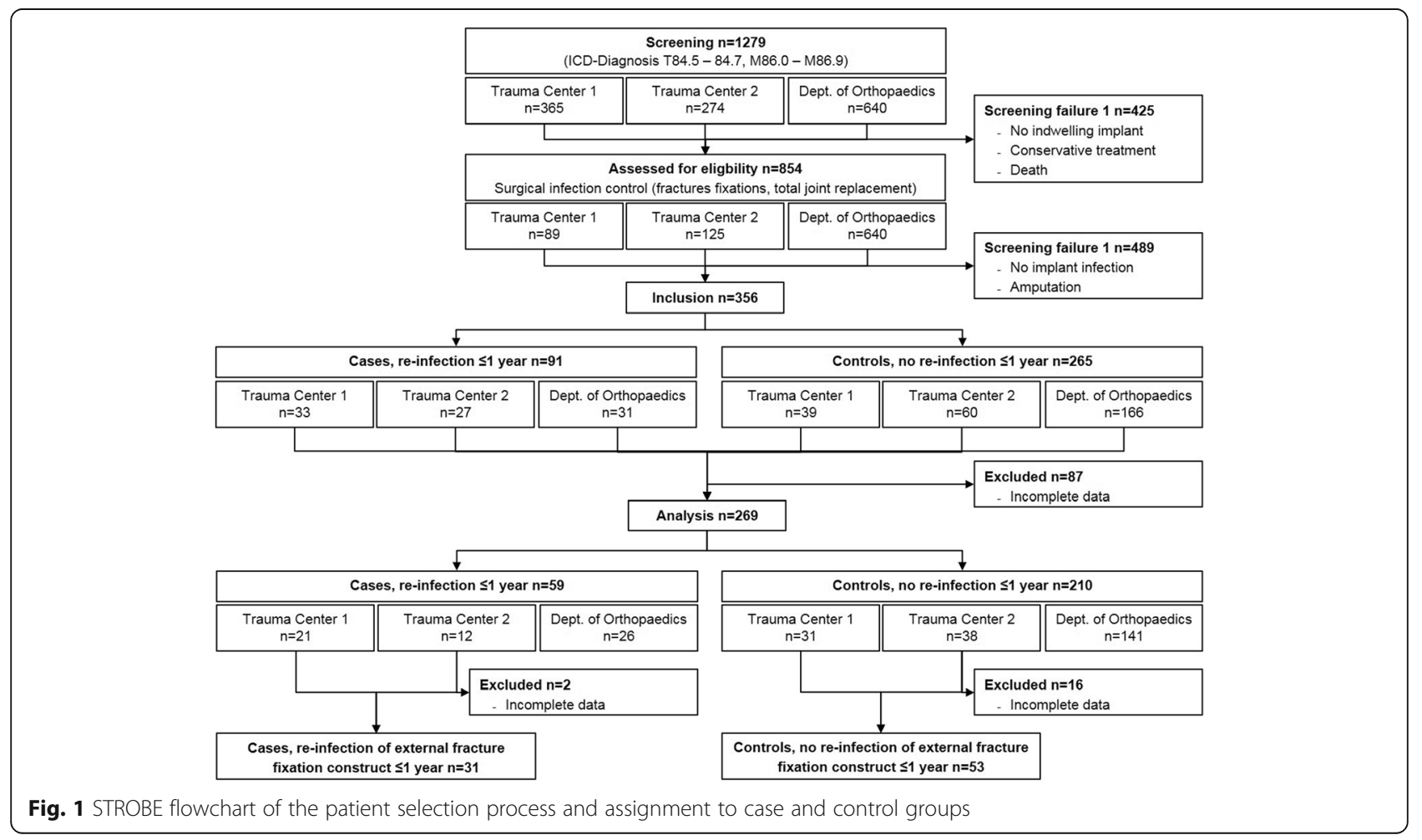


of a surgically obtained specimen. Sonication of explanted hardware and advanced molecular methods (e.g., PCR) contributed to the diagnosis of infection, although we did not investigate this in detail. Patients treated non-operatively, those who underwent amputation or died within 1 year after the last revision were excluded from the study. Patient demographics, risk profiles, details on infection and reinfection, surgical procedures, and antibiotic treatment were stored in a professional electronic data capture system (secuTrial ${ }^{\circ}$, interActive Systems GmbH, Berlin, Germany).

\section{Statistical analysis}

The primary endpoint of this study was reinfection within 1 year after the last surgical procedure intended to cure or control the primary infection. The primary exposition variable was duration of antibiotic treatment (number of days between the last surgical procedure and the last day of antibiotic medication). Due to its variance, it was dichotomized into "administration of systemic antibiotics < 14 days" and "administration of systemic antibiotics $\geq 14$ days". Secondary exposition variables were patient demographics, comorbidity (e.g., smoking, diabetes mellitus), American Society of Anesthesiologists physical status (ASA) classification, type of implant, microbial spectrum, local antibiotic treatment, antibiotics used, doses and routes of administration.

We provided raw numbers and percentages for categorical data. Continuous measures were expressed as means with standard deviations (SD) or medians with interquartile ranges (IQR), based on the underlying distribution and skewness. Where appropriate, we employed the $\mathrm{chi}^{2}$ or Kruskal-Wallis test for bivariate, exploratory group comparisons.

Uni- and multivariate logistic regression analysis were used for modelling the association between primary and secondary exposition variables and endpoints. Exposure variables with univariate $p$-values $<0.2$ and variables with a confounding effect were included in the model. To test possible confounding effects of secondary exposition variables, each of these variables were assessed by single logistic regression analyses. If unadjusted odds ratios (OR) differed from adjusted OR by $10 \%$, the secondary exposition variable was included in the model. We also used exact logistic regression analysis as a computationally more intensive tool which is regarded to provide more robust estimates in case of small sample sizes and skewed distributions [49].

For multivariate analysis in the infected fracture-fixation device scenario, age was categorized into quartiles. Days of systemic exposure to fluoroquinolones and rifampicin were clustered in clinically meaningful categories with comparable sample sizes. A first-order interaction term was introduced respecting combined fluoroquinolone-rifampicin antimicrobial therapy. Model fit and explained variance was assessed by the area under the receiver operating characteristics curve (AUC / ROC).

OR were calculated and reported with $95 \%$ confidence intervals (CI). Results with $p$-values $<0.05$ may be interpreted as incompatible with chance, although we did not go for inferential testing here. Statistical analysis employed SPSS (V22.0, IBM SPSS Statistics) and STATA (V14.0, Stata Corp., TX, USA).

\section{Results}

In total, electronic hospital databases revealed 1279 patients potentially eligible for this study. The screening and selection process resulted in complete data sets from 269 patients (59 cases, 210 controls) to be included in the statistical analysis. Of those, 84 (31 cases, 53 controls) had infections of extramedullary fracture fixation devices.

Thus, we roughly had a an overall ratio of cases to controls of 1: 4 , and a 1: 2 pairing with regard to

Table 1 Baseline profile, entire study population

\begin{tabular}{|c|c|c|}
\hline Variable & Cases & Controls \\
\hline$n$ & 59 & 210 \\
\hline Median age, years (IQR) & $63(48-71)$ & $67(55-73)$ \\
\hline \multicolumn{3}{|l|}{ Gender, n (\%) } \\
\hline Male & $42(71)$ & $106(50)$ \\
\hline Female & $17(29)$ & $104(50)$ \\
\hline Median BMI (IQR) & $28(25-32)$ & $28(25-33)$ \\
\hline Smoker, n (\%) & $20(34)$ & $42(20)$ \\
\hline Diabetes mellitus, n (\%) & $10(17)$ & $49(23)$ \\
\hline \multicolumn{3}{|l|}{ ASA status, n (\%) } \\
\hline 1 & $7(12)$ & $18(9)$ \\
\hline 2 & $28(47)$ & $98(47)$ \\
\hline$\geq 3$ & $24(41)$ & $94(45)$ \\
\hline \multicolumn{3}{|l|}{ Type of implant } \\
\hline Total joint arthroplasty & $28(47)$ & $157(75)$ \\
\hline Fracture fixation device & $31(53)$ & $53(25)$ \\
\hline \multicolumn{3}{|l|}{ Infection site } \\
\hline Lower extremity & $56(95)$ & $200(95)$ \\
\hline Upper extremity & $3(5)$ & $10(5)$ \\
\hline MRSA present, n (\%) & $3(5)$ & $6(3)$ \\
\hline \multicolumn{3}{|l|}{ Preferred antibiotics, n (\%) } \\
\hline Cefuroxime & $19(32)$ & $106(50)$ \\
\hline Moxifloxacin & $13(22)$ & $66(31)$ \\
\hline Clindamycin & $7(12)$ & $38(18)$ \\
\hline
\end{tabular}

$I Q R$ interquartile range, $B M I$ Body Mass Index, ASA American Society of Anesthesiologists physical status classification system, MRSA methicillinresistant staphylococcus aureus spec 
Table 2 Baseline profile, infected ORIF constructs only

\begin{tabular}{|c|c|c|c|}
\hline Variable & Cases & Controls & $p$ \\
\hline $\bar{n}$ & 31 & 53 & \\
\hline Median age, years (IQR) & $55(45-61)$ & $51(37-67)$ & 0.849 \\
\hline Gender, n (\%) & & & 0.706 \\
\hline Male & $20(65)$ & $32(60)$ & \\
\hline Female & $11(35)$ & $21(40)$ & \\
\hline Median BMI (IQR) & $\begin{array}{l}26.4 \\
(24.2-32.4)\end{array}$ & $\begin{array}{l}26.9 \\
(23.8-30.3)\end{array}$ & 0.513 \\
\hline Smoker, n (\%) & $12(39)$ & $18(34)$ & 0.661 \\
\hline Diabetes mellitus, n (\%) & $3(10)$ & $4(8)$ & 0.733 \\
\hline \multicolumn{4}{|l|}{ ASA status, n (\%) } \\
\hline 1 & $6(19)$ & $11(21)$ & 0.890 \\
\hline 2 & $16(52)$ & $28(53)$ & \\
\hline$\geq 3$ & $7(23)$ & $12(23)$ & \\
\hline unknown & $2(6)$ & $2(4)$ & \\
\hline Infection site & & & 0.487 \\
\hline Lower leg & $26(84)$ & $41(77)$ & \\
\hline Femur & $2(6)$ & $8(15)$ & \\
\hline Upper extremity & $3(10)$ & $4(8)$ & \\
\hline Additional IM nail, n (\%) & $2(6)$ & $7(13)$ & 0.334 \\
\hline \multicolumn{4}{|l|}{ Microbiology, n (\%) } \\
\hline MSSA & $21(68)$ & $24(45)$ & 0.046 \\
\hline MRSA & $3(10)$ & $3(6)$ & 0.490 \\
\hline CNS & $2(6)$ & $11(21)$ & 0.080 \\
\hline Enterococci & $3(10)$ & $12(23)$ & 0.134 \\
\hline Streptococci & $3(10)$ & $3(6)$ & 0.490 \\
\hline E. coli & 1 & 3 & \\
\hline Enterobacter spec. & 3 & 2 & \\
\hline Corynebacter spec. & 1 & 1 & \\
\hline Proteus spec. & 0 & 1 & \\
\hline Pseudomonas spec. & 2 & 2 & \\
\hline Peptostreptococci & 0 & 3 & \\
\hline Klebsiella spec. & 0 & 2 & \\
\hline Candida spec. & 0 & 1 & \\
\hline Local gentamicin, n (\%) & $6(19)$ & $10(19)$ & 0.956 \\
\hline \multicolumn{4}{|l|}{ Systemic antibiotics, n (\%) } \\
\hline Fluoroquinolones & $13(42)$ & $23(43)$ & 0.896 \\
\hline Rifampicin & $8(26)$ & $15(28)$ & 0.805 \\
\hline Cefuroxime & $6(19)$ & $14(26)$ & 0.463 \\
\hline Aminopenicillins & $9(29)$ & $9(17)$ & 0.194 \\
\hline Clindamycin & $2(6)$ & $5(9)$ & 0.633 \\
\hline Linezolid & 1 & 1 & \\
\hline Vancomycin & 0 & 2 & \\
\hline Gentamicin & 0 & 2 & \\
\hline Imipenem & 1 & 1 & \\
\hline
\end{tabular}

Table 2 Baseline profile, infected ORIF constructs only (Continued)

\begin{tabular}{|c|c|c|c|}
\hline Variable & Cases & Controls & $p$ \\
\hline Tazobactam & 1 & 2 & \\
\hline \multicolumn{4}{|l|}{ Combined fluoroquinolones and rifampicin } \\
\hline None & $29(55)$ & $18(58)$ & \\
\hline Any & $10(19)$ & $5(16)$ & \\
\hline Fluoroquinolones and / or rifampicin & $14(26)$ & $8(26)$ & \\
\hline
\end{tabular}

$I Q R$ interquartile range, BMI Body Mass Index, ASA American Society of Anesthesiologists physical status classification system, MSSA methicillinsensitive staphylococcus aureus spec, MRSA methicillin-resistant staphylococcus aureus spec, CNS coagulase-negative staphylococci

infected ORIF constructs. The study profile according to STROBE recommendations is shown in Fig. 1.

Sociodemographic and clinical characteristics of the eligible sample at the time of first revision are presented in Table 1. Case patients were more likely to be male smokers with an infected fracture fixation device. Most frequently prescribed antibiotics were cefuroxime, moxifloxacin, and clindamycin. Systemic antibiotic treatment up to 14 days was applied to $22(37 \%)$ case and 109 (52\%) control subjects. Correspondingly, 37 cases (63\%) and 101 controls (48\%) received prolonged treatment for $\geq 14$ days.

Univariate analysis suggested an increased risk of recurrent infection with longer antibiotic treatment (OR $1.82,95 \%$ CI 1.00 to $3.28, p=0.049$ ). Male gender (OR 2.42, $95 \%$ CI 1.30 to $4.53, p=0.005$ ), smoking (OR 2.05, 95\% CI 1.09 to $3.88, p=0.027)$, and infection of a fracture fixation device (OR 2.25, 95\% CI 1.21 to 4.2, $p=0.032$ ) were associated with an increased likelihood of developing relapse. In the multivariate model, male sex (OR 2.06, 95\% CI 1.08 to 3.94, $p=0.029$ ) and fracture fixation device infections (OR 2.05, 95\% CI 1.05 to $4.02, p=0.036$ ) remained predictors of reinfection. The odds of recurrence of implant-related infections was 1.85 higher for patients with antibiotic treatment lasting $\geq 14$ days than for those with treatment shorter than 14 days (OR 1.85, 95\% CI 0.99 to $3.48, p=0.055$ ).

Table 2 shows the profile of the patient subsample with extramedullary fracture device-associated infections. Altogether, key baseline criteria were well balanced across cases and controls. None of them were associated with the risk of recurrent infection by univariate analysis (Table 3). Univariate point estimates suggested a nearly $60 \%$ reduced odds of re-infection with systemic fluoroquinolones (OR 0.42, 95\% CI 0.04 to 2.46) or rifampicin treatment (OR $0.41,95 \% \mathrm{CI}$ 0.08 to 2.12) for up to 31 days, although the width of confidence intervals prohibited robust statistical or clinical inferences. 
Table 3 Results of univariate logistic regression and exact logistic regression analysis Baseline profile, infected ORIF constructs only

\begin{tabular}{|c|c|c|c|c|}
\hline Variable & Logistic regression, OR (95\% Cl) & $p$ & Exact logistic regression, OR (95\% Cl) & $p$ \\
\hline Age & $1.01(0.98-1.03)$ & 0.641 & $1.01(0.98-1.03)$ & 0.650 \\
\hline Male gender & $1.19(0.48-2.99)$ & 0.706 & $1.19(0.44-3.35)$ & 0.889 \\
\hline BMI & $1.02(0.96-1.08)$ & 0.598 & $1.02(0.95-1.08)$ & 0.601 \\
\hline Smoking & $1.23(0.49-3.08)$ & 0.661 & $1.23(0.44-3.38)$ & 0.836 \\
\hline Diabetes mellitus & $1.31(0.27-6.29)$ & 0.734 & $1.31(0.18-8.35)$ & 1.000 \\
\hline ASA class & $1.03(0.52-2.04)$ & 0.924 & $1.03(0.49-2.17)$ & 1.000 \\
\hline MRSA present & $1.79(0.34-9.45)$ & 0.495 & $1.77(0.22-14.15)$ & 0.779 \\
\hline Local antibiotics & $1.03(0.33-3.18)$ & 0.956 & $1.03(0.27-3.59)$ & 1.000 \\
\hline \multicolumn{5}{|l|}{ Systemic fluoroquinolones } \\
\hline Any use & $0.94(0.38-2.31)$ & 0.896 & $0.94(0.35-2.53)$ & 1.000 \\
\hline 1 to 7 days & $1.04(0.30-3.68)$ & 0.949 & $1.04(0.23-4.29)$ & 1.000 \\
\hline 8 to 31 days & $0.42(0.08-2.18)$ & 0.300 & $0.42(0.04-2.46)$ & 0.499 \\
\hline$>31$ days & $1.43(0.41-4.92)$ & 0.572 & $1.42(0.34-5.85)$ & 0.796 \\
\hline 1 to 31 days & $0.73(0.25-2.11)$ & 0.560 & $0.73(0.21-2.35)$ & 0.758 \\
\hline$>31$ days & $1.43(0.41-4.92)$ & 0.572 & $1.42(0.34-5.85)$ & 0.796 \\
\hline \multicolumn{5}{|l|}{ Systemic rifampicin } \\
\hline Any use & $0.88(0.32-2.40)$ & 0.805 & $0.88(0.28-2.64)$ & 1.000 \\
\hline 1 to 31 days & $0.41(0.08-2.12)$ & 0.289 & $0.42(0.04-2.35)$ & 0.476 \\
\hline$>31$ days & $1.42(0.42-4.74)$ & 0.572 & $1.41(0.35-5.60)$ & 0.790 \\
\hline Fluoroquinolones or rifampicin & $0.95(0.56-1.59)$ & 0.838 & & \\
\hline Either & $0.81(0.24-2.74)$ & 0.729 & $0.81(0.19-3.13)$ & 0.980 \\
\hline Combined & $0.92(0.32-2.63)$ & 0.877 & $0.92(0.28-2.94)$ & 1.000 \\
\hline
\end{tabular}

IQR interquartile range, $B M I$ Body Mass Index, ASA American Society of Anesthesiologists physical status classification system, MRSA methicillin-resistant staphylococcus aureus spec, MSSA methicillin-sensitive staphylococcus aureus spec, MRSA methicillin-resistant staphylococcus aureus spec, CNS coagulase-negative staphylococci

The best predictive multivariate model explained about $71 \%$ of infection recurrences and included age, gender, ASA class, the presence of various staphylococci, and exposure to systemic fluoroquinolones and rifampicin (Table 4 and Fig. 2). Individual OR are shown in a forest-plot format in Fig. 3.

\section{Discussion}

In this case-control study, we explored a mixed population with orthopaedic device-associated infections for potential predictive variables of infection recurrence after attempted curative surgery. We had a particular interest in studying the influence of the duration of systemic antimicrobial therapy on infection relapse. In the overall sample, male gender, smoking, and infection of a fracture fixation device were associated with an increased risk of subsequent reinfection.

Smoking is a well-known, modifiable risk factor for SSI and recurrent infection in orthopaedic surgery, both in elective total joint arthroplasty [50-57] and fracture care $[20,24,58,59]$, and ORs observed here were in line with previous investigations. As men are more likely to be active smokers than women, this may, in part,
Table 4 Results of multiivariate logistic regression regression analysis, infected ORIF constructs only

\begin{tabular}{lll}
\hline Variable & $\begin{array}{l}\text { Logistic regression, } \\
\text { OR }(95 \% \text { Cl) }\end{array}$ & $p$ \\
\hline Age (quartiles) & & \\
Male gender & $0.94(0.541-1.63)$ & 0.641 \\
ASA & $1.52(0.53-4.34)$ & 0.706 \\
MSSA present & $1.26(0.48-3.31)$ & 0.598 \\
MRSA present & $3.84(1.29-11.41)$ & 0.661 \\
CNS present & $2.16(0.36-13.13)$ & 0.734 \\
$\begin{array}{l}\text { Duration of fluoroquinolone } \\
\text { treatment (categorized) }\end{array}$ & $0.31(0.06-1.67)$ & 0.924 \\
$\begin{array}{l}\text { Duration of rifampicin } \\
\text { treatment (categorized) }\end{array}$ & $0.67(0.23-11.98)$ & 0.495 \\
Interaction & $0.17(0.01-5.45)$ & 0.956 \\
\hline ASA Ameican Society of Anestesiols
\end{tabular}

ASA American Society of Anesthesiologists physical status classification system, MSSA methicillin-sensitive staphylococcus aureus spec, MRSA methicillinresistant staphylococcus aureus spec, CNS coagulase-negative staphylococci 


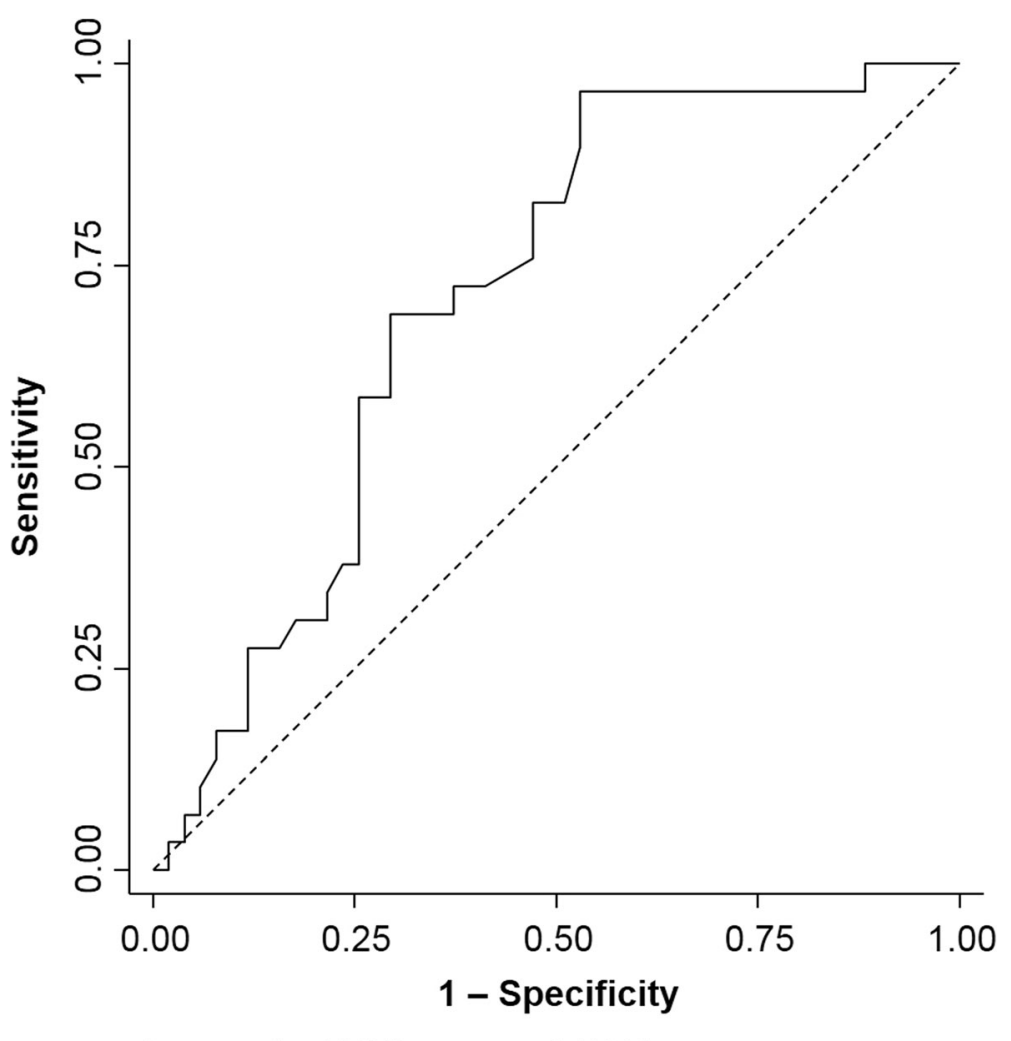

Area under ROC curve $=0.7113$

Fig. 2 Explained variance of the risk of recurrent extramedullary fracture-fixation-device-related infections by the final logistic regression model (Table 4), expressed by the area under the receiver operating characteristics curve (AUC / ROC)

contribute to the gender component observed in this and previous studies, although other (specifically genetic) effect modifiers need to be scrutinized in the near future $[24,60]$. The risk of reinfection with an indwelling fracture fixation device was almost 2.3 times higher compared to total joint arthroplasty. This is in accordance with previous studies [13, 61, 62].

The best explanation for the observed increased risk of recurrence with longer systemic antibiotic therapy (i.e. > 14 days) is that doctors opted for prolonged suppressive antimicrobial treatment because of patient- and disease-related characteristics not accessible by hospital and administrative chart documentation. It must not be concluded from the present data that prolonged systemic antibiotic therapy increases the risk of recurrent infection. This leads to the major limitations of this study-it was retrospective, used hospital chart data, and, after applying predefined selection criteria, enrolled a rather small sample of patients.

We did not account for single- and two-stage revision protocols in infected total joint arthroplasties, and patients with subsequent reinfections may have consulted another hospital, thereby introducing verification bias.
We had deliberately chosen a case-control design as orthopaedic device-associated infections in the developed countries are serious but comparably rare events, and the incidence of reinfection after an index infection currently remains unpredictable. In this situation, a case-control strategy is generally more efficient than a cohort approach to estimate possible effect sizes but only allows for limited causal inference between exposure and outcome variables. A major lesion learned from this study is that it is almost impossible to derive scientifically precise and unequivocal information about process and outcome parameters in septic orthopaedic surgery from current hospital documentation systems. Detailed assessment of patients' charts is necessary to obtain clinically relevant data, and to abstract the individual course from initial presentation over surgical procedures to discharge and follow-up.

Regarding the subsample of patients with infected fracture-fxation devices, both the presence of staphylococci as well as systemic treatment with fluoroquinolones and rifampicin for about 30 days predicted the risk of reinfection, although the sample size and study design did not allow for robust conclusions. Because of the small sample size, the final model also may have been saturated. 


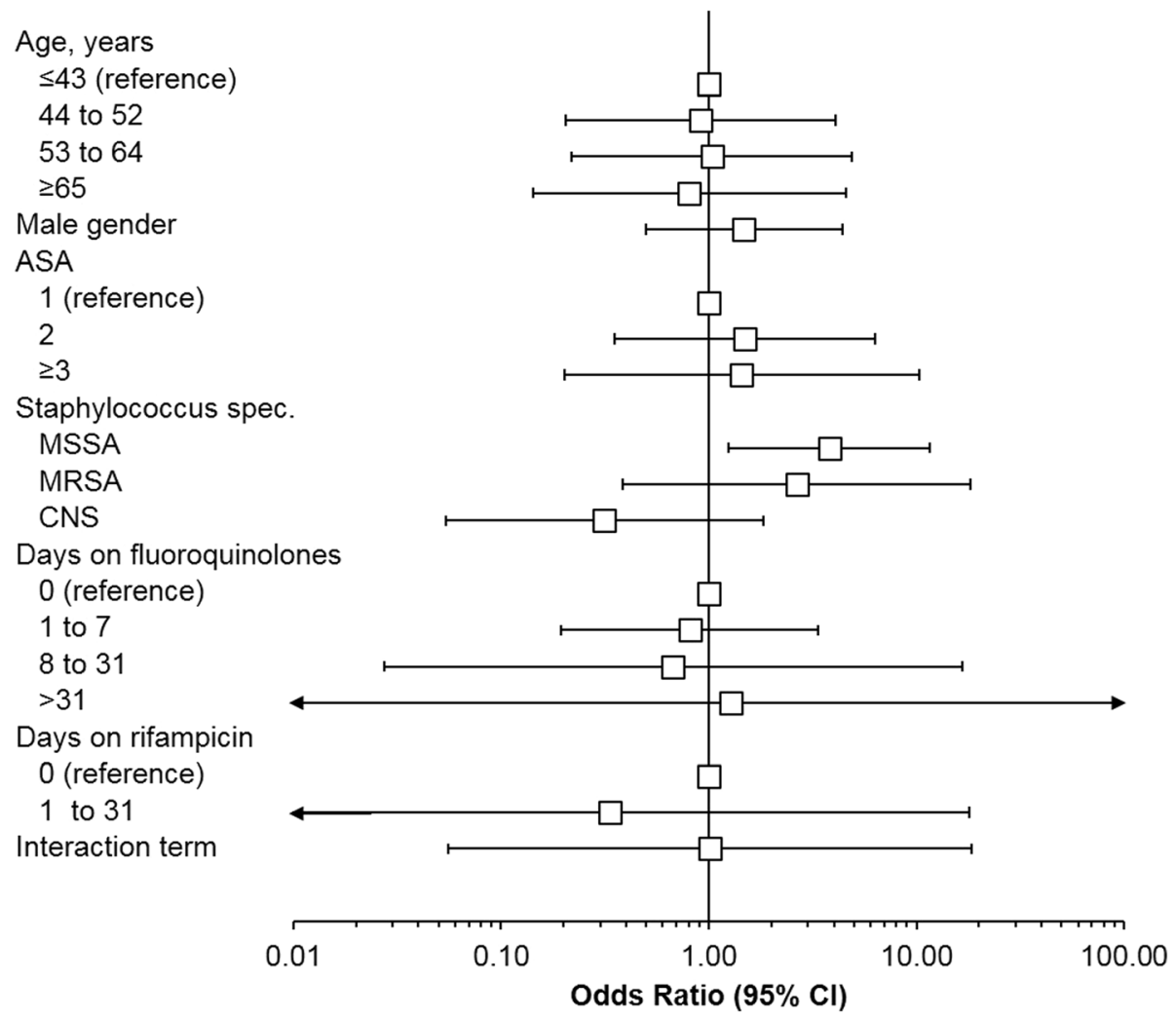

Fig. 3 Forest plot of individual odds ratios (OR) and 95\% confidence intervals (CI) obtained from the final multivariate logistic model (Table 4)

Answering the important question whether prolonged suppressive systemic antimicrobial treatment reduces the risk of reinfection clearly demands a multicenter RCT. This, however, needs to be conducted under EMA (European Medicines Agency), FDA (US Food and Drug Administration), and other international pharmaceutical regulations, with major requirements on trial logistics. Assuming a baseline risk of infection of 5\% for any anatomical site, fracture severity, soft tissue compromise and so on, two-sided type I and II errors of $2 \%$ (accounting for multiple testing) and 15\% (including a power reserve), respectively, a trial aiming at demonstrating a relative risk reduction of $50 \%$ by prolonged (i.e., $\geq 31$ days) over shorter systemic antimicrobial treatment must recruit about $2 \times 1400$ patients, depending on the preferred adaptive design, number of interim analyses, strata etc. One may also think of a non-inferiority trial demonstrating that shorter systemic antibiotic treatment (e.g., 30 days) is not inferior to longer application with regard to infection relapse. This will, however, demand even higher sample sizes. We call for a European initiative to investigate the optimal duration of systemic antibiotic therapy for patients with fracture-fixation-device-associated infections undergoing revision surgery. This may, apart from standardizing diagnostic, peri-operative, surgical, and aftercare protocols, identify the most effective empiric systemic antibiotic regimen for patients suffering from deep SSI, namely device-related infections, adhering to the principles of antibiotic stewardship.

\section{Conclusion}

In summary, up to 31 days of systemic exposure to fluoroquinolones and / or rifampicin appear to lower the risk of reinfection after surgical revision for infected extramedullary fracture-fixation constructs, although present results are compatible with chance. A large-scale confirmatory trial is needed to confirm that prolonged systemic suppressive antibiotic therapy is more effective than shorter administration in reducing reinfections, or that shorter treatment is not inferior to prolonged exposure in achieving this endpoint.

\section{Acknowledgements}

The authors thank Ms. Antje Völker, Ms. Kristin Werner and Dr. Martin Ellenrieder for their support in collecting data.

\section{Funding}

The study was supported by the German Ministry of Education and Research (Bundesministerium für Bildung und Forschung, BMBF, grant number 01KQ1001B). The funder was not involved in planning, conduct or analysis of the study.

\section{Availability of data and materials}

Anonymized datasets are available from the corresponding author on request following a data sharing and transparency policy. 


\section{Authors' contributions}

$R S, A E$, and DS conceived the study. RS, SZ, CG and DS set up the methods. $S Z$, AK and RS created the CRFs. DG and MN interpreted data regarding fracture fixation devices, and WM and RB interpreted data regarding total joint arthroplasties. AK collected, analyzed and interpreted the microbiology data. CG and DS statistical analyzed the data. RS and DS wrote the paper. All authors have read and approved the manuscript.

\section{Ethics approval and consent to participate}

This study was approved by the Institutional Review Board of the University Medicine of Greifswald, Germany, under the reference number BB026/13. We employed retrospective pseudonymized data, and no written informed consent needed to be obtained from patients according to German data protection laws and common GCP standards.

\section{Consent for publication}

Not applicable.

\section{Competing interests}

The authors declare that they have no competing interests.

\section{Publisher's Note}

Springer Nature remains neutral with regard to jurisdictional claims in published maps and institutional affiliations.

\begin{abstract}
Author details
${ }^{1}$ Department of Trauma, Reconstructive Surgery and Rehabilitation Medicine, University Medicine Greifswald, Ferdinand-Sauerbruch-Str, 17475 Greifswald, Germany. ${ }^{2}$ Department of Trauma and Orthopaedic Surgery, BG Hospital Unfallkrankenhaus Berlin gGmbH, Warener Str 7, 12683 Berlin, Germany. ${ }^{3}$ Center for Clinical Research, BG Hospital Unfallkrankenhaus Berlin gGmbH, Warener Str 7, 12683 Berlin, Germany. ${ }^{4}$ Department of Orthopaedics, University Medicine Rostock, Doberaner Str 142, 18057 Rostock, Germany. ${ }^{5}$ Department of Hygiene and Environmental Medicine, University Medicine Greifswald, Walther-Rathenau-Str 49A, 17489 Greifswald, Germany. ${ }^{6}$ BG Kliniken Group of Hospitals, Leipziger PI 1, 10117 Berlin, Germany.
\end{abstract}

Received: 12 July 2018 Accepted: 15 April 2019

Published online: 01 May 2019

\section{References}

1. Bozic KJ, Kurtz SM, Lau E, Ong K, Chiu V, Vail TP, Rubash HE, Berry DJ. The epidemiology of revision total knee arthroplasty in the United States. Clin Orthop Relat Res. 2010;468(1):45-51.

2. Patel A, Pavlou G, Mujica-Mota RE, Toms AD. The epidemiology of revision total knee and hip arthroplasty in England and Wales: a comparative analysis with projections for the United States. A study using the National Joint Registry dataset. Bone Joint J. 2015:97-B(8):1076-81.

3. Delanois RE, Mistry JB, Gwam CU, Mohamed NS, Choksi US, Mont MA. Current epidemiology of revision Total knee arthroplasty in the United States. J Arthroplast. 2017;32(9):2663-8.

4. Kapadia BH, Berg RA, Daley JA, Fritz J, Bhave A, Mont MA. Periprosthetic joint infection. Lancet. 2016;387(10016):386-94

5. Lenguerrand E, Whitehouse MR, Beswick AD, Kunutsor SK, Burston B, Porter $\mathrm{M}, \mathrm{Blom}$ AW. Risk factors associated with revision for prosthetic joint infection after hip replacement: a prospective observational cohort study. Lancet Infect Dis. 2018;18(9):1004-14.

6. Sullivan E, Gupta A, Cook CH. Cost and consequences of surgical site infections: a call to arms. Surg Infect. 2017:18(4):451-4.

7. Lamagni T. Epidemiology and burden of prosthetic joint infections. Antimicrob Chemother. 2014;69(Suppl 1):i5-10.

8. Makela KT, Matilainen M, Pulkkinen P, Fenstad AM, Havelin L, Engesaeter L, Furnes $\mathrm{O}$, Pedersen AB, Overgaard S, Karrholm J, et al. Failure rate of cemented and uncemented total hip replacements: register study of combined Nordic database of four nations. BMJ (Clinical research ed). 2014; 348:f7592.

9. Lenguerrand $E$, Whitehouse MR, Beswick AD, Jones SA, Porter ML, Blom AW. Revision for prosthetic joint infection following hip arthroplasty: evidence from the National Joint Registry. Bone Joint Res. 2017;6(6):391-8.

10. Badawy M, Espehaug B, Fenstad AM, Indrekvam K, Dale H, Havelin LI, Furnes $O$. Patient and surgical factors affecting procedure duration and revision risk due to deep infection in primary total knee arthroplasty. BMC Musculoskelet Disord. 2017:18(1):544

11. Beswick AD, Elvers KT, Smith AJ, Gooberman-Hill R, Lovering A, Blom AW. What is the evidence base to guide surgical treatment of infected hip prostheses? Systematic review of longitudinal studies in unselected patients. BMC Med. 2012;10:18

12. Al-Mayahi M, Betz M, Muller DA, Stern R, Tahintzi P, Bernard L, Hoffmeyer $P$, Suva D, Uckay I. Remission rate of implant-related infections following revision surgery after fractures. Int Orthop. 2013;37(11):2253-8.

13. Kunutsor SK, Whitehouse MR, Lenguerrand E, Blom AW, Beswick AD, Team I. Re-infection outcomes following one- and two-stage surgical revision of infected knee prosthesis: a systematic review and meta-analysis. PLoS One. 2016;11(3):e0151537.

14. Darouiche RO. Treatment of infections associated with surgical implants. N Engl J Med. 2004;350(14):1422-9.

15. Gaunder CL, Zhao Z, Henderson C, McKinney BR, Stahel PF, Zelle BA. Wound complications after open reduction and internal fixation of tibial plateau fractures in the elderly: a multicentre study. Int Orthop. 2019;43(2):461-65.

16. Henkelmann R, Frosch KH, Glaab R, Lill H, Schoepp C, Seybold D, Josten C, Hepp P. Infection following fractures of the proximal tibia - a systematic review of incidence and outcome. BMC Musculoskelet Disord. 2017;18(1):481

17. Li J, Zhu Y, Liu B, Dong T, Chen W, Zhang Y. Incidence and risk factors for surgical site infection following open reduction and internal fixation of adult tibial plateau fractures. Int Orthop. 2018;42(6):1397-403.

18. Ma Q, Aierxiding A, Wang G, Wang C, Yu L, Shen Z. Incidence and risk factors for deep surgical site infection after open reduction and internal fixation of closed tibial plateau fractures in adults. Int Wound J. 2018;15(2):237-42.

19. Meng J, Sun T, Zhang F, Qin S, Li Y, Zhao H. Deep surgical site infection after ankle fractures treated by open reduction and internal fixation in adults: a retrospective case-control study. Int Wound J. 2018;15(6):971-7.

20. Shao J, Chang H, Zhu Y, Chen W, Zheng Z, Zhang H, Zhang Y. Incidence and risk factors for surgical site infection after open reduction and internal fixation of tibial plateau fracture: A systematic review and meta-analysis. Int J Surg (London, England). 2017;41:176-82

21. Shao J, Zhang H, Yin B, Li J, Zhu Y, Zhang Y. Risk factors for surgical site infection following operative treatment of ankle fractures: A systematic review and meta-analysis. Int J Surg (London, England). 2018;56:124-32.

22. Sun R, Li M, Wang X, Li X, Wu L, Chen Z, Chen K. Surgical site infection following open reduction and internal fixation of a closed ankle fractures: A retrospective multicenter cohort study. Int J Surg (London, England). 2017:48:86-91.

23. Rares Mircea Birlutiu VB, Mihalache M, Mihalache C, Cismasiu RS. Diagnosis and management of orthopedic implant-associated infection: a comprehensive review of the literature. Biomed Res. 2017:28:5063-73.

24. Kortram K, Bezstarosti H, Metsemakers WJ, Raschke MJ, Van Lieshout EMM, Verhofstad MHJ. Risk factors for infectious complications after open fractures; a systematic review and meta-analysis. Int Orthop. 2017:41(10):1965-82.

25. Investigators F, Bhandari M, Jeray KJ, Petrisor BA, Devereaux PJ, HeelsAnsdell D, Schemitsch EH, Anglen J, Della Rocca GJ, Jones C, et al. A trial of wound irrigation in the initial management of open fracture wounds. $\mathrm{N}$ Engl J Med. 2015;373(27):2629-41.

26. Markatos K, Kaseta M, Nikolaou VS. Perioperative Skin Preparation and Draping in Modern Total Joint Arthroplasty: Current Evidence. Surg Infect. 2015;16(3):221-5.

27. Gillespie WJ, Walenkamp GH: Antibiotic prophylaxis for surgery for proximal femoral and other closed long bone fractures. Cochrane Database Syst Rev 2010;(3):Cd000244

28. Wang J, Zhu C, Cheng T, Peng X, Zhang W, Qin H, Zhang X. A systematic review and meta-analysis of antibiotic-impregnated bone cement use in primary total hip or knee arthroplasty. PLoS One. 2013:8(12):e82745.

29. Berrios-Torres SI, Umscheid CA, Bratzler DW, Leas B, Stone EC, Kelz RR, Reinke CE, Morgan S, Solomkin JS, Mazuski JE, et al. Centers for Disease Control and Prevention guideline for the prevention of surgical site infection, 2017. JAMA Surg. 2017;152(8):784-91.

30. Hallak G, Neuner B, Schefold JC, Gorzelniak K, Rapsch B, Pfuller R, Stengel D, Wellmann J, Ekkernkamp A, Walter M. Preemptive isolation precautions of patients at high risk for methicillin-resistant Staphylococcus aureus in combination with Ultrarapid polymerase chain reaction screening as an effective tool for infection control. Infect Control Hosp Epidemiol. 2016. 37(12):1489-91. 
31. Hacek DM, Robb WJ, Paule SM, Kudrna JC, Stamos VP, Peterson LR. Staphylococcus aureus nasal decolonization in joint replacement surgery reduces infection. Clin Orthop Relat Res. 2008;466(6):1349-55.

32. Kawamura H, Matsumoto K, Shigemi A, Orita M, Nakagawa A, Nozima S, Tominaga H, Setoguchi T, Komiya S, Tokuda K, et al. A bundle that includes active surveillance, contact precaution for carriers, and cefazolin-based antimicrobial prophylaxis prevents methicillin-resistant Staphylococcus aureus infections in clean orthopedic surgery. Am J Infect Control. 2016; 44(2):210-4.

33. Rao N, Cannella B, Crossett LS, Yates AJ Jr, McGough R 3rd. A preoperative decolonization protocol for staphylococcus aureus prevents orthopaedic infections. Clin Orthop Relat Res. 2008;466(6):1343-8.

34. Chen AF, Wessel CB, Rao N. Staphylococcus aureus screening and decolonization in orthopaedic surgery and reduction of surgical site infections. Clin Orthop Relat Res. 2013:471(7):2383-99.

35. Vallier HA, Super DM, Moore TA, Wilber JH. Do patients with multiple system injury benefit from early fixation of unstable axial fractures? The effects of timing of surgery on initial hospital course. J Orthop Trauma. 2013:27(7):405-12.

36. Vallier HA, Wang X, Moore TA, Wilber JH, Como JJ. Timing of orthopaedic surgery in multiple trauma patients: development of a protocol for early appropriate care. J Orthop Trauma. 2013;27(10):543-51.

37. Lasanianos NG, Kanakaris NK, Dimitriou R, Pape HC, Giannoudis PV. Second hit phenomenon: existing evidence of clinical implications. Injury. 2011; 42(7):617-29.

38. Koek MBG, Hopmans TEM, Soetens LC, Wille JC, Geerlings SE, Vos MC, van Benthem BHB, de Greeff SC. Adhering to a national surgical care bundle reduces the risk of surgical site infections. PLoS One. 2017;12(9):e0184200.

39. Bert F, Giacomelli S, Amprino V, Pieve G, Ceresetti D, Testa M, Zotti CM. The "bundle" approach to reduce the surgical site infection rate. J Eval Clin Pract. 2017;23(3):642-7.

40. Schweizer ML, Chiang HY, Septimus E, Moody J, Braun B, Hafner J, Ward MA, Hickok J, Perencevich EN, Diekema DJ, et al. Association of a bundled intervention with surgical site infections among patients undergoing cardiac, hip, or knee surgery. Jama. 2015;313(21):2162-71.

41. Kurtz $\mathrm{S}$, Ong K, Lau E, Mowat F, Halpern M. Projections of primary and revision hip and knee arthroplasty in the United States from 2005 to 2030. J Bone Joint Surg Am. 2007:89(4):780-5.

42. Societe de Pathologie Infectieuse de Langue F, College des Universitaires de Maladies Infectieuses et T, Groupe de Pathologie Infectieuse P, Societe Francaise d'Anesthesie et de R, Societe Francaise de Chirurgie Orthopedique et T, Societe Francaise d'Hygiene $\mathrm{H}$, Societe Francaise de Medecine N, Societe Francaise de Medecine Physique et de R, Societe Francaise de $\mathrm{M}$, Societe Francaise de $\mathrm{R}$, et al. Recommendations for bone and joint prosthetic device infections in clinical practice (prosthesis, implants, osteosynthesis). Societe de Pathologie Infectieuse de Langue Francaise. Med Mal Infect. 2010;40(4):185-211.

43. Osmon DR, Berbari EF, Berendt AR, Lew D, Zimmerli W, Steckelberg JM, Rao $\mathrm{N}$, Hanssen A, Wilson WR, Infectious Diseases Society of A. Executive summary: diagnosis and management of prosthetic joint infection: clinical practice guidelines by the Infectious Diseases Society of America. Clin Infect Dis. 2013;56(1):1-10.

44. Parvizi J, Gehrke T, Chen AF. Proceedings of the international consensus on Periprosthetic joint infection. Bone Joint J. 2013;95-B(11):1450-2.

45. Minassian AM, Osmon DR, Berendt AR. Clinical guidelines in the management of prosthetic joint infection. J Antimicrob Chemother. 2014; 69(Suppl 1):i29-35.

46. Ellenrieder M, Lenz R, Haenle M, Bader R, Mittelmeier W. Two-stage revision of implant-associated infections after total hip and knee arthroplasty. GMS Krankenhhyg Interdiszip. 2011;6(1):Doc17.

47. Walter G, Kemmerer M, Kappler C, Hoffmann R. Treatment algorithms for chronic osteomyelitis. Deutsches Arzteblatt international. 2012; 109(14):257-64.

48. Hoiby N, Bjarnsholt T, Moser C, Bassi GL, Coenye T, Donelli G, Hall-Stoodley L, Hola V, Imbert C, Kirketerp-Moller K, et al. ESCMID guideline for the diagnosis and treatment of biofilm infections 2014. Clin Microbiol Infect. 2015;21(Suppl 1):S1-25.

49. Wilson JR, Lorenz KA. Exact Logistic Regression Model. In: Modeling Binary Correlated Responses using SAS, SPSS and R. edn. Cham: Springer International Publishing; 2015. p. 147-65.
50. Zhu Y, Zhang F, Chen W, Liu S, Zhang Q, Zhang Y. Risk factors for periprosthetic joint infection after total joint arthroplasty: a systematic review and meta-analysis. J Hosp Infect. 2015;89(2):82-9.

51. Singh JA, Schleck C, Harmsen WS, Jacob AK, Warner DO, Lewallen DG Current tobacco use is associated with higher rates of implant revision and deep infection after total hip or knee arthroplasty: a prospective cohort study. BMC Med. 2015;13:283.

52. Rodriguez-Merchan EC. The importance of smoking in orthopedic surgery. Hosp Pract (1995). 2018;46(4):175-82.

53. Kunutsor SK, Whitehouse MR, Blom AW, Beswick AD. Patient-related risk factors for Periprosthetic joint infection after Total joint arthroplasty: a systematic review and meta-analysis. PLoS One. 2016;11(3):e0150866.

54. Eka A, Chen AF. Patient-related medical risk factors for periprosthetic joint infection of the hip and knee. Ann Transl Med. 2015;3(16):233.

55. Duchman KR, Gao Y, Pugely AJ, Martin CT, Noiseux NO, Callaghan JJ. The effect of smoking on short-term complications following Total hip and knee arthroplasty. J Bone Joint Surg Am. 2015;97(13):1049-58.

56. Bedard NA, DeMik DE, Owens JM, Glass NA, DeBerg J, Callaghan JJ. Tobacco use and risk of wound complications and Periprosthetic joint infection: a systematic review and meta-analysis of primary Total joint arthroplasty procedures. J Arthroplast. 2019;34(2):385-396.e4

57. Alamanda VK, Springer BD. Perioperative and modifiable risk factors for Periprosthetic joint infections (PJI) and recommended guidelines. Curr Rev Musculoskelet Med. 2018;11(3):325-31.

58. Truntzer J, Vopat B, Feldstein M, Matityahu A. Smoking cessation and bone healing: optimal cessation timing. Eur J Orthop Surg Traumatol. 2015;25(2):211-5.

59. Scolaro JA, Schenker ML, Yannascoli S, Baldwin K, Mehta S, Ahn J. Cigarette smoking increases complications following fracture: a systematic review. J Bone Joint Surg Am. 2014;96(8):674-81.

60. Resende VAC, Neto AC, Nunes C, Andrade R, Espregueira-Mendes J, Lopes S. Higher age, female gender, osteoarthritis and blood transfusion protect against periprosthetic joint infection in total hip or knee arthroplasties: a systematic review and meta-analysis. Knee Surg Sports Traumatol Arthrosc. 2018.

61. Rightmire E, Zurakowski D, Vrahas M. Acute infections after fracture repair: management with hardware in place. Clin Orthop Relat Res. 2008;466(2):466-72.

62. Kubista B, Hartzler RU, Wood CM, Osmon DR, Hanssen AD, Lewallen DG. Reinfection after two-stage revision for periprosthetic infection of total knee arthroplasty. Int Orthop. 2012;36(1):65-71.

Ready to submit your research? Choose BMC and benefit from:

- fast, convenient online submission

- thorough peer review by experienced researchers in your field

- rapid publication on acceptance

- support for research data, including large and complex data types

- gold Open Access which fosters wider collaboration and increased citations

- maximum visibility for your research: over $100 \mathrm{M}$ website views per year

At $\mathrm{BMC}$, research is always in progress.

Learn more biomedcentral.com/submissions 